\title{
Effect of Lipopolysaccharide (LPS) Exposure on the Reproductive Organs of Immature Female Rats
}

\author{
Da Kyung Yoo and ${ }^{\dagger}$ Sung-Ho Lee \\ Dept. of Life Science, Sangmyung University, Seoul 03016, Korea
}

\begin{abstract}
Lipopolysaccharide (LPS), an endotoxin, elicits strong immune responses in mammals. Several lines of evidence demonstrate that LPS challenge profoundly affects female reproductive function. For example, LPS exposure affects steroidogenesis and folliculogenesis, resulting in delayed puberty onset. The present study was conducted to clarify the mechanism underlying the adverse effect of LPS on the delayed puberty in female rats. LPS was daily injected for 5 days (50 $\mu \mathrm{g} / \mathrm{kg}$, PND 25-29) to treated animals and the date at VO was evaluated through daily visual examination. At PND 39, animals were sacrificed, and the tissues were immediately removed and weighed. Among the reproductive organs, the weights of the ovaries and oviduct from LPS-treated animals were significantly lower than those of control animals. There were no changes in the weights of uterus and vagina between the LPS-treated and their control animals. Immunological challenge by LPS delayed VO. Multiple corpora lutea were found in the control ovaries, indicating ovulations were occurred. However, none of corpus luteum was present in the LPS-treated ovary. The transcription level of steroidogenic acute regulatory protein (StAR), CYP11A1, CYP17A1 and CYP19 were significantly increased by LPS treatment. On the other hand, the levels of $3 \beta-$ HSD, $17 \beta$-HSD and LH receptor were not changed by LPS challenge. In conclusion, the present study demonstrated that the repeated LPS exposure during the prepubertal period could induce multiple alterations in the steroidogenic machinery in ovary, and in turn, delayed puberty onset. The prepubertal LPS challenge model used in our study is useful to understand the reciprocal regulation of immune (stress) - reproductive function in early life.
\end{abstract}

Key words : Lipopolysaccharide (LPS), Delayed puberty onset, Ovary, Steroidogenesis, Rat

\section{INTRODUCTION}

Lipopolysaccharide (LPS), also known as an endotoxin, is a large molecule consisting of a lipid and a polysaccharide. LPS is found in the outer membrane of Gram-negative bacteria, and elicits strong immune responses in mammals (Raetz \& Whitfield, 2002). Several lines of evidence demonstrate that LPS challenge profoundly affects reproductive function. In male rats, intraperitoneal injection of LPS induced oxidative stress that leads to functional damages in the testicular mitochondria, and eventually, impairment of spermatogenesis (Aly et al., 2012). Also, direct injection of LPS into the caput region of the rat epididymis induced epididymitis, and this can decrease the expression of epididymal beta-defensins (SPAG11E), causing the impairment of sperm motility (Cao et al., 2010).

In female rats, LPS affects in vitro secretion of sex steroid hormones from both theca-interstital cells and granulosa

\footnotetext{
Manuscript received April 15, 2016, Received in revised form April 20, 2016, Accepted April 24, 2016

${ }^{\dagger}$ Corresponding Author : Sung-Ho Lee, Dept. of Life Science, Sangmyung University, Seoul 03016, Korea. Tel. : +82-2-2287-5139, Fax : +82-2-22870070, E-mail : shlee@smu.ac.kr

This is an Open Access article distributed under the terms of the Creative Commons Attribution Non-Commercial License (http:// creativecommons.org/licenses/by-nc/3.0) which permits unrestricted non-commercial use, distribution, and reproduction in any medium, provided the original work is properly cited.
} 
cells (Taylor \& Terranova, 1995; Taylor \& Terranova, 1996). Systemic treatment with LPS and prolactin significantly increased the number of atretic follicles in pro-estrus ovaries and increased the apoptotic cells and macrophages (Besnard et al., 2001). In addition, prenatal or neonatal LPS exposure significantly delayed the day of vaginal opening (VO) in female rats (Izvolskaia et al., 2016; Cardoso et al., 2009), These studies suggest that LPS might affect the ovarian steroidogenesis and folliculogenesis. However, the exact mechanism underlying the adverse effect of LPS on the female reproduction is not clearly understood yet.

In the present study, we hypothesized that LPS treatment during adolescence can change the timing of puberty onset which is associated with altered ovarian steroidogenesis. To explore the hypothesis, we used prepubertal female rats and chronic LPS treatment model, and measured transcriptional activities of steroidogenesis related genes in ovary.

\section{MATERIALS \& METHODS}

\section{Animals}

Timely pregnant Sprague-Dawley rats were obtained from Han-Lim Animal (Gyunggi-do, Korea) and reared in Sangmyung University animal facility under conditions of 12-h light/dark cycle (lights on at 07:00 h) and constant temperature of $22 \pm 1^{\circ} \mathrm{C}$. During pregnancy and lactation, the mothers had free access to normal chow and tap water (ad libitum). All procedures used were approved by the Animal Care and Use Committee at Sangmyung University in accordance with guidelines established by the Korea Food and Drug Administration (KFDA).

\section{Experimental design}

The day after weaning, female dams were randomly assigned to control and LPS-treated group ( $n=6-8 /$ group) and their body weights were checked from PND 25 until sacrifice. Rats were treated chronically (for 5 days, from PND 25 -
29) with LPS (from Escherichia coli 0128:B12, SigmaAldrich, Korea) which was dissolved in sterile saline. LPS (50 $\mu \mathrm{g} / \mathrm{kg}$ body weight; injection volume, $0.3 \mathrm{~mL}$ ) were daily injected (ip) at 09:00 to treated animals and control animals with saline $(0.9 \%)$. The date (age) at VO was evaluated through daily visual examination. At PND 39, animals were sacrificed and the tissues (ovary, uterus, oviduct, vagina, adrenal, spleen and thymus) were immediately removed and weighed at 18:00.

\section{Histology}

Seminal Vesicle tissue specimens were fixed 4\% paraformaldehyde at $4^{\circ} \mathrm{C}$ for $24 \mathrm{~h}$. Fixed tissues were serially dehydrated in graded ethanol and xylene. Specimens were embedded in paraffin block. The tissues blocks were cut at $6 \mu \mathrm{m}$ using microtome (HM350S, MICROM, Germany). Sections were stained with hematoxylin-eosin stain and examined under light microscope (BX51, Olympus, Japan).

\section{Total RNA extraction and reverse transcriptase} PCR analyses

Total RNAs were isolated from tisssue samples using the single-step, acid guanidinum thiocyanate-phenol-chloroform extraction method. Total RNAs were used in RTPCR reactions carried out with Maxime ${ }^{\mathrm{TM}}$ RT PreMix (InTron, Korea) and Accupower PCR Premix (GeneAll, Korea) according to the manufacturer's instructions. Sequences of the primers and the specific PCR conditions used in this study are listed in Tables 1 and 2, respectively. The reaction products were analysed by gel electrophoresis in $1.5 \%$ agarose gel, $75 \mathrm{~V} 65 \mathrm{~min}$ and visualized by ethidium bromide staining. The band intensities were measured using the image analysis system (Imager III -1D main soft ware, Bioneer, Korea).

\section{Statistical analysis}

All values are expressed as the means $( \pm$ S.E. $)$. Differences 
Table 1. Sequences of the primers used in this study

\begin{tabular}{|c|c|c|c|}
\hline Gene & $\begin{array}{l}\text { Accession } \\
\text { number }\end{array}$ & Sequence of the primers & $\begin{array}{l}\text { Product } \\
\text { size (bp) }\end{array}$ \\
\hline StAR & NM031558 & $\begin{array}{l}\text { F 5'- AAA CTG ACT CCA GAG TGC TC } \\
\text { R 5'- TGT CCT TCA CTG TCA GCT TC }\end{array}$ & 528 \\
\hline CYP11A1 & J05156 & $\begin{array}{l}\text { F 5'- CAT CAA GGA GAC ACT GAG AC } \\
\text { R 5'- GCA TCA GGA TGA GGT TGA AC }\end{array}$ & 368 \\
\hline CYP17A1 & NM012753 & $\begin{array}{l}\text { F 5'- CAC CAA CTT TCA ATG ACC GG } \\
\text { R 5'- GCT ACT GCA GAG GTT TGA CT }\end{array}$ & 372 \\
\hline $3 \beta-H S D$ & NM001007719 & $\begin{array}{l}\text { F 5'- CCA CTT GGT CAC ACT GTC AA } \\
\text { R 5'- CTG AGG CAT AAC TAC CTG TG }\end{array}$ & 367 \\
\hline $17 \beta$-HSD & $\mathrm{BC} 061543$ & $\begin{array}{l}\text { F 5'- GGA ACA GAT CCC AGA ATG AC } \\
\text { R 5'- ACA GAC ATG ACC AAC ACT GG }\end{array}$ & 498 \\
\hline CYP19 & NM017085 & $\begin{array}{l}\text { F 5'- CGT CAT GTT GCT TCT CAT CG } \\
\text { R 5'- TCA ATC ACG TCA TCC TCC AG }\end{array}$ & 204 \\
\hline LH-R & NM012978 & $\begin{array}{l}\text { F 5'- CCT GAG CAT CTG TAA CAC AG } \\
\text { R 5'- CTG TGC ATC TTC TCC AGG TA }\end{array}$ & 266 \\
\hline GAPDH & NM017008 & $\begin{array}{l}\text { F 5'- CCA TCA CCA TCT TCC AGG AG } \\
\text { R 5'- CCT GTT TCA CCA CCT TCT TG }\end{array}$ & 576 \\
\hline
\end{tabular}

F, forward; R, reverse. The directions of sequences are all $5^{\prime}$ to $3^{\prime}$.

Table 2. Specific conditions of PCRs used in this study

\begin{tabular}{ccc}
\hline \hline Gene & $\begin{array}{c}\text { Temperature \& Time } \\
\text { Denature } / \text { Annealing } / \text { Extension }\end{array}$ & $\begin{array}{c}\text { Number } \\
\text { of cycle }\end{array}$ \\
\hline StAR & $94^{\circ} \mathrm{C}, 40 \mathrm{sec} / 61^{\circ} \mathrm{C}, 1 \mathrm{~min} / 72^{\circ} \mathrm{C}, 1 \mathrm{~min}$ & 35 \\
CYP11A1 & $94^{\circ} \mathrm{C}, 30 \mathrm{sec} / 65^{\circ} \mathrm{C}, 40 \mathrm{sec} / 72^{\circ} \mathrm{C}, 40 \mathrm{sec}$ & 35 \\
CYP17A1 & $94^{\circ} \mathrm{C}, 40 \mathrm{sec} / 64^{\circ} \mathrm{C}, 1 \mathrm{~min} / 72^{\circ} \mathrm{C}, 1 \mathrm{~min}$ & 33 \\
$3 \beta$-HSD & $94^{\circ} \mathrm{C}, 30 \mathrm{sec} / 61^{\circ} \mathrm{C}, 40 \mathrm{sec} / 72^{\circ} \mathrm{C}, 40 \mathrm{sec}$ & 38 \\
$17 \beta-H S D$ & $94^{\circ} \mathrm{C}, 30 \mathrm{sec} / 61^{\circ} \mathrm{C}, 40 \mathrm{sec} / 72^{\circ} \mathrm{C}, 40 \mathrm{sec}$ & 35 \\
CYP19 & $94^{\circ} \mathrm{C}, 30 \mathrm{sec} / 60^{\circ} \mathrm{C}, 40 \mathrm{sec} / 72^{\circ} \mathrm{C}, 40 \mathrm{sec}$ & 33 \\
LH-R & $94^{\circ} \mathrm{C}, 30 \mathrm{sec} / 61^{\circ} \mathrm{C}, 40 \mathrm{sec} / 72^{\circ} \mathrm{C}, 40 \mathrm{sec}$ & 32 \\
GAPDH & $94^{\circ} \mathrm{C}, 30 \mathrm{sec} / 61^{\circ} \mathrm{C}, 40 \mathrm{sec} / 72^{\circ} \mathrm{C}, 40 \mathrm{sec}$ & 24 \\
\hline
\end{tabular}


between control and treatment groups were analysed by Student's $t$-test. $P$ values less than 0.05 were considered significant. The IBM PC programs INSTAT and PRISM 3.0 (GraphPad, San Diego, CA, USA) were used to calculate and plot the results.

\section{RESULTS}

1. Changes in the body weights and the day of vaginal opening

There was no difference in the body weights between the LPS-treated and their control animals from PND 25 until PND 38 (Fig. 1). On the other hand, immunological challenge by LPS during PND 25-29 delayed VO (Controls vs LPS-treated group $=37.50 \pm 0.83$ vs $39.50 \pm 1.37, P<0.05)$, as clearly shown in Fig. 2. The day all the animals exerted VO was PND 41.

\section{Changes in the tissue weights}

In order to evaluate a potential adverse effect of LPS on

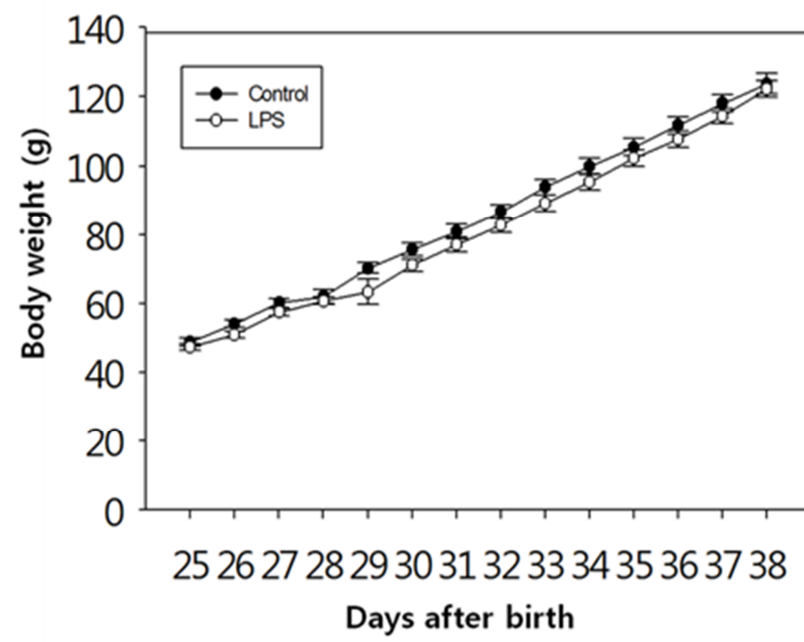

Fig. 1. Effect of LPS exposure on changes in body weights of female rats and tissues weights from PND 25 until PND 38. Animals were injected daily during PND 25-29 with LPS (50 $\mu \mathrm{g} / \mathrm{kg}$ body weight/day; injection volume, $0.3 \mathrm{~mL})$ or $0.9 \%$ Saline $(0.3 \mathrm{~mL}$, Control) for 5 days.

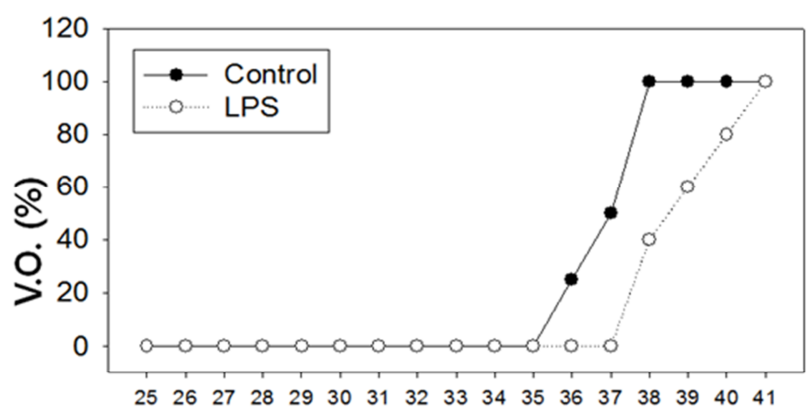

PND

Fig. 2. Effect of LPS exposure on changes in date of vaginal opening (VO) of female rats.

the reproductive organs, we measured the tissue weights of ovary, uterus, oviduct and vagina; Adrenal, spleen and thymus weights served as non-reproductive organs (Table 3). The animal sacrifice was scheduled at PND 39, since the majority of control animals failed to show VO while all LPS-treated animals exerted VO on the date (Fig. 2). Among the reproductive organs, the weights of the ovaries from LPS-treated animals were significantly lower than those of control animals $(12.7 \pm 0.5 \mathrm{mg} v s 19.5 \pm 1.4 \mathrm{mg}$, $p<0.001)$. Likewise, the weights of the oviduct from LPStreated animals were significantly lower than those of controls (4.8 $\pm 0.3 \mathrm{mg} v s 6.5 \pm 0.3 \mathrm{mg}, p<0.001)$. However, there were no changes in the weights of uterus and vagina between the LPS-treated and their control animals. Nonreproductive tissues such as adrenal, spleen and thymus failed to show any weight difference between controls and LPS-treated animals.

\section{Ovarian and uterine histology}

To access the histological changes in LPS-exposured ovaries and uteri, standard paraffin section and hematoxylineosin staining method were employed (Fig. 3). Multiple corpora lutea were found in the control ovaries, indicating ovulations were occurred in this animals. However, none of corpus luteum was present in LPS-treated ovary; instead, 
Table 3. Comparison of tissue weights between control and LPS-treated rats at PND 39

\begin{tabular}{cccc}
\hline \hline & & Control & LPS \\
\hline & Ovary & $19.5 \pm 1.4$ & $12.7 \pm 0.5^{* * *}$ \\
$\begin{array}{c}\text { Reproductive } \\
\text { organs (mg) }\end{array}$ & Oviduct & $6.5 \pm 0.3$ & $4.8 \pm 0.3^{* * *}$ \\
& Uterus & $66.5 \pm 5.1$ & $63.9 \pm 8.7$ \\
& Vagina & $77.8 \pm 7.1$ & $84.1 \pm 9.9$ \\
\hline $\begin{array}{c}\text { Non- } \\
\text { reproductive } \\
\text { organs }\end{array}$ & Sdrenal (mg) & $11.4 \pm 0.7$ & $11.5 \pm 0.4$ \\
& Thymus (g) & $0.48 \pm 0.02$ & $0.44 \pm 0.01$ \\
& Pituitary (mg) & $6.9 \pm 0.4$ & $5.9 \pm 0.2$ \\
\hline
\end{tabular}

*** $P<0.001$ vs. control (n=8 per group).

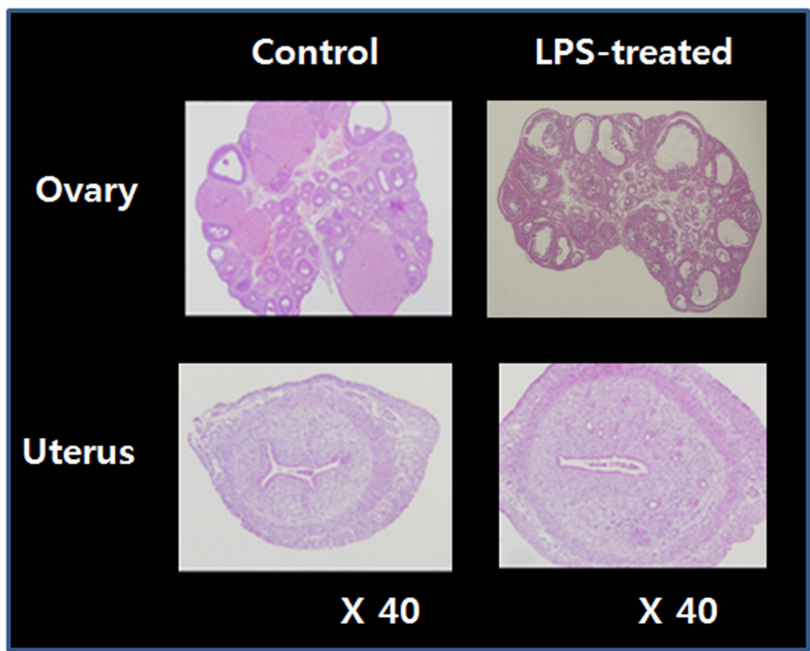

Fig. 3. Histology of the ovaries and uteri from control and LPS-treated rats. The tissues were collected at PND 39, then were applied to the standard paraffin section and hematoxylin-eosin staining method. Note on the presence of corpora lutea in the control ovary, and of degenerating follicles in the LPS-treated ovary.

several degenerating (atretic) and cyst-like follicles were found. Uteri of LPS-treated animals shown the slightly thickened endometrial and myometrial layers and lessdeveloped luminal structures compared to control uteri.

4. RT-PCRs of ovarian steroidogenesis-related transcripts

To address the relationship between the delayed puberty onset and the ovarian steroidogeneic activities in the LPSexposured rats, we employed semi-quantitative RT-PCRs. Fig. 4A shows that the transcription level of steroidogenic acute regulatory protein (StAR) was significantly increased by LPS treatment (Control vs LPS-treated group $=1.0 \pm 0.3$
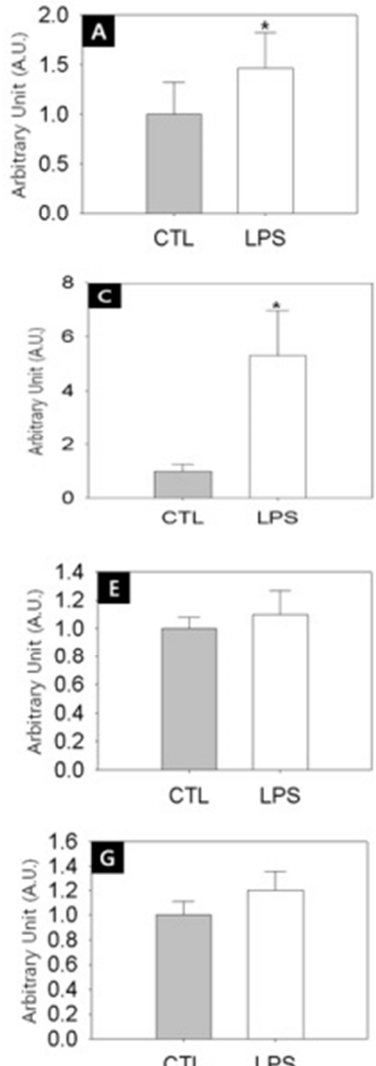

Fig. 4. Measurement of the transcript levels of the seven steroidogenesis-related genes in the ovaries from controls and LPS-treated animals. On PND 39, the ovaries were collected and applied to RNA extraction. RT-PCRs were performed using the specific primers and conditions described in Tables 1 and 2. Values are expressed as mean \pm S.E. $(n=6-8$ per group). *, Significantly different from control group, $p<0.05$. $^{* * *}$, Significantly different from control group, $p<0.001$. 
A.U. $v s 1.5 \pm 0.4$ A.U., $p<0.05)$. StAR is a transport protein that regulates cholesterol transfer within the mitochondria, which is the rate-limiting step in the production of steroid hormones. Likewise, the transcription levels of CYP11A1 (Fig. 4B, Control vs LPS-treated group $=1.0 \pm 0.4$ A.U. $v s$ 4.6 \pm 0.6 A.U., $p<0.001$ ). CYP17A1 (Fig. 4C, Control vs LPS-treated group $=1.0 \pm 0.2$ A.U. vs $5.3 \pm 1.7$ A.U., $p<0.05$ ), CYP19 (Fig. 4F, Control vs LPS-treated group $=1.0 \pm 0.2$ A.U. $v s 4.5 \pm 1.6$ A.U., $p<0.05$ ) were significantly increased by LPS treatment. CYP11A1 is a cholesterol side-chain cleavage enzyme, commonly referred to as P450scc, and this is a mitochondrial enzyme that catalyzes conversion of cholesterol to pregnenolone. CYP17A1, also called cytochrome P450 17A1 or steroid $17 \alpha$-hydroxylase, is a key enzyme in the steroidogenic pathway that produces progestins, mineralocorticoids, glucocorticoids, androgens, and estrogens. CYP19, also called aromatase, is responsible for the aromatization of androgens into estrogens.

On the other hand, the transciption levels of 3 3 -HSD (Fig. 4D), 17ß-HSD (Fig. 4E) and LH receptor (Fig. 4G)

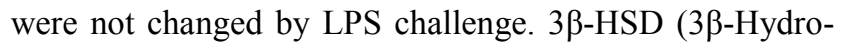
xysteroid dehydrogenase/ $\Delta 5-4$ isomerase) is an enzyme that catalyzes the biosynthesis of progesterone from pregnenolone. 17 $\beta$-HSD (17 $\beta$-Hydroxysteroid dehydrogenases) is a key enzyme that catalyze the final steps of the steroid biosynthesis.

\section{DISCUSSION}

In the present study, we demonstrate that the immune challenge by prepubertal LPS injection resulted in delayed puberty onset and significant decreased transcriptional activities of the steroidogenesis-related genes in rat ovary. Previously published researches also shown that the delayed VO, a widely accepted vital sign of puberty onset, was observed in female rats with different LPS-exposure timimg; in utero (Izvolskaia et al., 2016), neonatal (Knox et al., 2009), neonatal and postwean (Ozgocer et al., 2015) and postwean (Cardoso et al., 2010). The methodological differences of LPS exposure between ours and the Cardoso et al. (2010) were number of dosage [PND 25-29 (daily) vs PND 25, 27 and 29], strains of animal (Sprague Dawley vs Wistar) and serotypes (Escherichia coli 0128:B12 vs Salmonella typhosa). Different exposure time and duration, dose, and origin of bacterial strains can elicit differential immunological response (Appelmelk et al., 1993). However, based on the studies including our own, it is reasonable that LPS might be a highly potent immune agent which can induce delayed puberty onset in female rats with a wide range of effectiveness.

It is well known that immune stress affects the reproductive system and could act at the different levels of the hypothalamic-pituitary-gonadal axis (HPG), most of all at the level of the brain (Herman et al., 2010). In the brain, LPS might play a suppressive role on the GnRH neuronal activity through the stimulation of the negative inputs such as opioid and GABA. Administration of LPS inhibited steroid-induced LH release and reduced the Fos expression in GnRH neurones, and pretreatment with LPS inhibited naloxone-induced $\mathrm{LH}$ release in adult female rats (He et al., 2003). In the following study, LPS significantly increased the content of glutamic acid decarboxylase 67 (GAD67), a GABA-synthesising enzyme, in the medial preoptic area (mPOA), and this LPS challenge completely eliminated the steroid-induced LH surge (Akema et al., 2005). The authors suggested that LPS stimulates GABA synthesis in preoptic neurones, which in turn inhibits the LH surge in female rats. This idea was supported by the facts that intraperitoneal LPS administrations during prepubertal period significantly increased $\mathrm{GnRH}$ and glutamate contents but decreased GABA content in the hypothalamus of peripubertal female rats (Cordoso et al., 2010). According to the authors, the tissue contents inversely correlated with the release of GnRH/glutamate/GABA. LPS can also acts on the hypothalamic kisspetin neurons, an upstream modulator of GnRH 
pulse generator. Neonatal LPS exposure resulted in the down-regulation of Kiss1 expression in the mPOA of prepubertal females rats, suggesting that the mPOA population of kisspeptin neurones play a pivotal role in controlling the onset of puberty, and that their function can be affected by neonatal stress such as immune challenge (Knox et al., 2009).

There are enough evidence to prove both of direct and indirect LPS actions on ovary. Systemic LPS treatment (over a period of 6 days) induced a state of constant dioestrus and decreased circulating concentrations of progesterone and estradiol, and resulted in significantly fewer large preovulatory follicles in adult rats (Shakil et al., 1994). In another systemic treatment study, LPS and prolactin significantly increased the number of atretic follicles and increased the mean number of apoptotic cells and macrophages in proestrus ovaries (Besnard et al., 2001). In the two classic in vitro studies, treatment of rat theca-interstital cells with LPS led to a dose-dependent decrease in LH-stimulated progesterone and androstenedione secretion (Taylor \& Terranova, 1995), and treatment of rat granulosa cells with LPS led to a significant dose-dependent decrease in LHstimulated estradiol accumulation in culture media (Taylor $\&$ Terranova, 1996). The authors also demonstrated that the LPS had no significant effect on LH receptor level, and suggested that the effect appears to be restricted to the LHstimulated aromatization of androgens to estrogen. LPS, therefore, appears to have a direct suppressive effect in ovarian functions, possibly via an inhibitory action on steroidogenesis (Shakil et al., 1994). Our findings that chronic LPS exposure elicits the changes in the expressions of steroidogenesis-related genes in rat ovary support this hypothesis.

It is intriguing that the expression of the steroidogenesisrelated genes are differentially regulated in brain, testis and adrenal with tissue-specific manner. LPS administration induced similar oxidative damages and altered several gene expressions in the brain and testis of adult male rats; the mRNA expression of $3 \beta-H S D$ and $17 \beta-H S D$ was increased in the brain with significant decrease in the testis in LPS treated animals (Sadasivam et al., 2014). The authors also demonstrated that the LPS treatment completely represses androgen receptor co-repressor (ARR19) in the brain while not in the testis, and suggested that the opposite expression patterns in the brain and testis are attributed to the tissue-specific expression of ARR19. Similar to this, our results show that the expression levels of ovarian $3 \beta$-HSD and 17 $\beta$-HSD remained unchanged in LPS-exposured rats. In mice study, no change in StAR mRNA was detected in the testis while increments of StAR protein and mRNA in the adrenal (Hales et al., 2000). Our finding that increase of ovarian StAR expression by LPS treatment is close to adrenal pattern rather than testis one.

In conclusion, the present study demonstrated that the repeated LPS exposure during the prepubertal period induced multiple alterations in the steroidogenic machinery in ovary, and resulted in delayed puberty onset. Delayed puberty is tightly connected with reduced level of sex steroids at an appropriate age, short stature and decreased self-esteem. Although malnutrition is probably the most important mechanism responsible for delayed puberty, chronic illness is accompanied by a delay in growth and the pubertal growth spurt, and therefore, early diagnosis is essential and appropriate and specific therapy fundamental (Pozo \& Argente, 2002). In that sense, prepubertal LPS challenge model is useful to understand the consequences of chronic or frequent bacterial infection in early life and the reciprocal regulation of immune (stress) - reproductive function.

\section{ACKNOWLEDGEMENT}

This research was supported by a 2014 Research Grant from Sangmyung University. 


\section{REFERENCES}

Akema T, He D, Sugiyama H (2005) Lipopolysaccharide increases gamma-aminobutyric acid synthesis in medial preoptic neurones in association with inhibition of steroid-induced luteinising hormone surge in female rats. J Neuroendocrinol 17:672-678.

Aly HA, El-Beshbishy HA, Banjar ZM (2012) Mitochondrial dysfunction induced impairment of spermatogenesis in LPS-treated rats: Modulatory role of lycopene. Eur J Pharmacol 29;677:31-38.

Appelmelk BJ, Maaskant JJ, Verweij-van Vught AM, van der Meer NM, Thijs BG, MacLaren DM (1993) Antigenic and immunogenic differences in lipopolysaccharides of Escherichia coli J5 vaccine strains of different origins. J Gen Microbiol 139:2641-2647.

Besnard N, Horne EA, Whitehead SA (2001) Prolactin and lipopolysaccharide treatment increased apoptosis and atresia in rat ovarian follicles. Acta Physiol Scand 172: $17-25$.

Cao D, Li Y, Yang R, Wang Y, Zhou Y, Diao H, Zhao Y, Zhang Y, Lu J (2010) Lipopolysaccharide-induced epididymitis disrupts epididymal beta-defensin expression and inhibits sperm motility in rats. Biol Reprod 83: 1064-1070.

Cardoso N, Arias P, Szwarcfarb B, Ponzo O, Carbone S, Moguilevsky J, Scacchi P, Reynoso RM (2010) Reproductive axis response to repeated lipopolysaccharide administration in peripubertal female rats. J Physiol Biochem 66:237-244.

Hales KH, Diemer T, Ginde S, Shankar BK, Roberts M, Bosmann HB, Hales DB (2000) Diametric effects of bacterial endotoxin lipopolysaccharide on adrenal and Leydig cell steroidogenic acute regulatory protein. Endocrinology141:4000-4012.

He D, Sato I, Kimura F, Akema T (2003) Lipopolysaccharide inhibits luteinizing hormone release through interaction with opioid and excitatory amino acid inputs to gonadotropin-releasing hormone neurones in female rats: Possible evidence for a common mechanism involved in infection and immobilization stress. J Neuroendocrinol 15:559-563.

Herman AP, Romanowicz K, Tomaszewska-Zaremba D (2010) Effect of LPS on reproductive system at the level of the pituitary of anestrous ewes. Reprod Domest Anim 45:e351-359.

Izvolskaia MS, Tillet Y, Sharova VS, Voronova SN, Zakharova LA (2016) Disruptions in the hypothalamicpituitary-gonadal axis in rat offspring following prenatal maternal exposure to lipopolysaccharide. Stress 19:198205.

Knox AM, Li XF, Kinsey-Jones JS, Wilkinson ES, Wu XQ, Cheng YS, Milligan SR, Lightman SL, O'Byrne KT (2009) Neonatal lipopolysaccharide exposure delays puberty and alters hypothalamic Kiss1 and Kiss1r mRNA expression in the female rat. J Neuroendocrinol 21: 683-689.

Ozgocer T, Yildiz S, Elbe H, Vardi N. (2015) Endotoxin exposure and puberty in female rats: The role of nitric oxide and caspase-1 inhibition in neonates. Can J Physiol Pharmacol 93:603-614.

Pozo J, Argente J (2002) Delayed puberty in chronic illness. Best Pract Res Clin Endocrinol Metab 16:73-90.

Raetz CR, Whitfield C (2002) Lipopolysaccharide endotoxins. Ann Rev Biochem 71:635-700.

Sadasivam M, Ramatchandirin B, Ayyanar A, Prahalathan C (2014) Bacterial lipopolysaccharide differently modulates steroidogenic enzymes gene expressions in the brain and testis in rats. Neurosci Res 83:81-88.

Shakil T, Snell A, Whitehead SA (1994) Effects of lipopolysaccharide and cyclosporin on the endocrine control of ovarian function. J Reprod Fertil 100:57-64.

Taylor CC, Terranova PF (1995) Lipopolysaccharide inhibits rat ovarian thecal-interstitial cell steroid secretion in 
vitro. Endocrinology 136:5527-5532.

Taylor CC, Terranova PF (1996) Lipopolysaccharide inhibits in vitro luteinizing hormone-stimulated rat ovarian granulosa cell estradiol but not progesterone secretion. Biol Reprod 54:1390-1396. 